\title{
Childhood neuroblastoma masquerading as pheochromocytoma: case report
}

This article was published in the following Dove Press journal:

International Medical Case Reports Journal

17 March 2016

Number of times this article has been viewed

\section{Suk-Bae Moon \\ Department of Surgery, Kangwon National University Hospital, Kangwon National School of Medicine, Kangwon National University, Chuncheon, South Korea}

\begin{abstract}
Neuroblastoma is the most common extracranial solid tumor in children. Mild hypertension is a frequent symptom, presumably an effect of catecholamines that tumors release. Reported herein is the rare occurrence of severe hypertension and subsequent heart failure attributable to adrenal gland neuroblastoma. A 3-year-old boy presented with anterior chest wall protrusion. Physical examination revealed severe hypertension, and left-sided cardiac failure was evident by echocardiography. Catecholamine metabolite (norepinephrine) levels were increased in serum $(>2,000 \mathrm{pg} / \mathrm{mL})$ and in urine $(1,350.5 \mu \mathrm{g} /$ day $)$. Abdominal computed tomography scan showed a $7 \mathrm{~cm}$ solid mass arising from right adrenal gland. Oral phenoxybenzamine was given for hemodynamic stabilization, and right adrenalectomy was performed to remove an apparent pheochromocytoma. Ultimately, the pathologic diagnosis was ganglioneuroblastoma. Both hypertension and cardiac failure resolved postoperatively.
\end{abstract}

Keywords: hypertension, heart failure, adrenal gland, pheochromocytoma

\section{Introduction}

Neuroblastoma (NBL) is the most common extracranial solid tumor in childhood that derives from the neural crest and may vary in clinical symptoms, depending on location, distal spread, and secreted metabolites of tumors. ${ }^{1}$ Pheochromocytoma is also a neural crest-derived tumor that presents with headache, fever, palpitation, and weight loss, but the most common presentation is sustained hypertension. ${ }^{2}$ Hypertension secondary to catecholamine release is manifested in $\sim 25 \%$ of patients with NBL, but it is generally not severe compared to that in pheochromocytoma. ${ }^{1}$ Described herein is the case of a 3-year-old boy who suffered severe hypertension and heart failure due to adrenal gland NBL.

\section{Case report}

This study was conducted in accord with all the guidelines stipulated by the Declaration of Helsinki. Because no interventional experimentation whatsoever was involved and the study was retrospective, written patient consent and ethics committee approval was not required by the Institutional Review Board of Kangwon National University Hospital.

A 3-year-old boy presented to our facility with anterior chest wall protrusion. His birth record and past medical history were unremarkable. On physical examination, a protruding anterior bony chest wall was obvious, and systolic blood pressure elevation was recorded (160-200 $\mathrm{mmHg}$ ). In addition to marked cardiomegaly visible 
Table I Blood and 24-hour urine catecholamine levels

\begin{tabular}{llll}
\hline & Catecholamine & Preoperative & Postoperative \\
\hline Blood & Epinephrine $(\mathrm{pg} / \mathrm{mL})$ & $84.25(<50)$ & N/A \\
& Norepinephrine $(\mathrm{pg} / \mathrm{mL})$ & $>2,000(110-140)$ & N/A \\
& Dopamine $(\mathrm{pg} / \mathrm{mL})$ & $>2,000(<87)$ & N/A \\
24-Hour & Epinephrine $(\mu \mathrm{g} / \mathrm{day})$ & $4.75(0-20)$ & $\mathrm{N} / \mathrm{A}$ \\
urine & Norepinephrine $(\mu \mathrm{g} /$ day) & $1,350.5(15-80)$ & $\mathrm{N} / \mathrm{A}$ \\
& Dopamine $(\mu \mathrm{g} /$ day $)$ & $717.8(65-400)$ & $\mathrm{N} / \mathrm{A}$ \\
& VMA $(\mathrm{mg} /$ day $)$ & $57.1(<3.0)$ & 1.0 \\
\hline
\end{tabular}

Note: Data in parenthesis refers to laboratory reference range. Abbreviations: N/A, not available; VMA, vanillylmandelic acid.

on plain chest radiograph, echocardiography revealed left-sided heart failure (ejection fraction, 27\%) and mitral valve regurgitation. Laboratory testing disclosed elevated levels of catecholamines and their metabolites (Table 1). Abdominal computed tomography (CT) images revealed a heterogeneously enhanced, solid, and rounded tumor of right adrenal gland, measuring $7 \times 6.5 \mathrm{~cm}$ (Figure 1). For what appeared to be pheochromocytoma, the patient was given a 2-week antihypertensive regimen of phenoxybenzamine, nitroprusside, and nitroglycerin. Open adrenalectomy was then performed, free of drastic blood pressure fluctuations during surgery. Postoperative hypotension was controlled by a 24 -hour dopamine drip $(5 \mu \mathrm{g} / \mathrm{kg} / \mathrm{h})$, tapered thereafter. The final pathologic examination was ganglioneuroblastoma intermixed type (Figure 2).

This patient's hospital course was uneventful, with abatement of both hypertension and cardiac failure following surgery. By International Neuroblastoma Staging System (INSS) criteria, a negative postoperative workup for metastasis, including bone marrow examination, bone scan, and iodine-131-meta-iodobenzylguanidine whole-body scan, indicated stage I disease. His baseline vanillylmandelic acid level of $57.1 \mathrm{mg} /$ day (normal for age, $<18 \mathrm{mg}$ /day) declined to $1.0 \mathrm{mg} /$ day at postoperative Month 1. By postoperative Month 8, six cycles of chemotherapy were completed (without signs of NBL recurrence), his chest wall no longer protruded, and the cardiomegaly was resolving.

\section{Discussion}

NBL is a neuroendocrine tumor arising in sympathetic nerves. A significant proportion of patients are known to develop mild secondary hypertension from tumor-produced catecholamines. ${ }^{3,4}$ However, severe hypertension, culminating in heart failure, is rarely reported. In prior accounts, a 3 -year-old boy ${ }^{5}$ and a 5 -year-old girl ${ }^{6}$ who similarly developed severe hypertension due to adrenal tumors have been described. Likewise, these lesions were indistinguishable preoperatively from pheochromocytoma but proved to be NBL after adrenalectomy. Cho et al also reported a 7-yearold boy who experienced cardiac failure during the course of chemotherapy for NBL. ${ }^{7}$ The rarity of this symptom complex prompts a diagnosis of pheochromocytoma rather than NBL, based on clinical evidence.

A diagnosis of pheochromocytoma typically stems from hallmark features, including catecholamine metabolite elevations in blood and urine, using radiologic tests for localization. Usually, homogeneous enhancement is found on CT or magnetic resonance scans of pheochromocytomas, but heterogeneous enhancement is feasible (thus mimicking NBL) if a tumor necrosis occurs. ${ }^{8}$ In the absence of tissue confirmation, NBL with excessive catecholamine production and pheochromocytoma may thus be impossible to differentiate by blood and/or radiologic testing. ${ }^{9}$ Positron emission tomography may be a useful imaging study for pheochromocytoma in the near future, and if specific agent, such as 6-(18F)-fluorodopamine, becomes generally available,

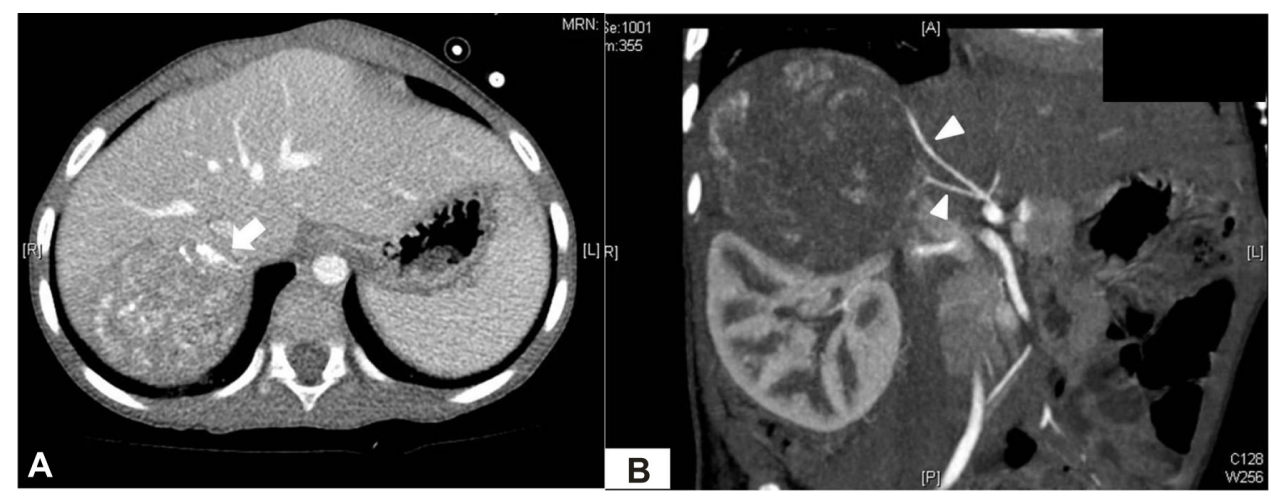

Figure I Preoperative CT scan.

Notes: (A) Axial view of heterogeneously enhanced mass $(7 \times 6 \mathrm{~cm})$ with internal calcification (arrow), arising from right adrenal gland. (B) Branches of right phrenic artery (arrowheads) supplying blood to tumor.

Abbreviation: CT, computed tomography. 


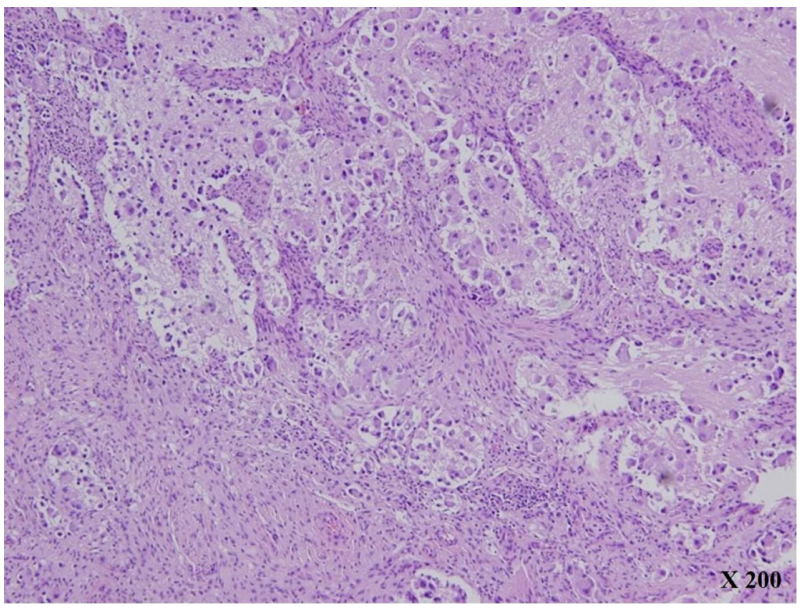

Figure 2 Histologic features $(\mathrm{H} \& \mathrm{E}, \times 200)$.

Note: The figure shows the prominent Schwannian stromal development ( $>50 \%$ ) punctuated by residual neuroblastic cells in various stages of differentiation.

Abbreviation: H\&E, hematoxylin and eosin.

positron emission tomography scanning may prove to be the imaging method of choice. ${ }^{2}$ Our preliminary impression of pheochromocytoma was correctly diagnosed as NBL after surgery.

Activation of the renin-angiotensin system by renal artery compression is another known mechanism of hypertension due to adrenal NBL. ${ }^{10}$ Although plasma renin or aldosterone determinations were lacking in our patient, renovascular hypertension is excluded by CT evidence (ie, absence of vascular compression) and documented catecholamine elevations in blood and urine.

Use of alpha1-adrenergic blockers, such as phenoxybenzamine, for preoperative hemodynamic stabilization is of paramount importance in treating pheochromocytoma but has not been investigated in NBL-associated hypertension. However, this preoperative strategy did prove successful here, given that alpha1-adrenergic receptors are also implicated in the hemodynamic volatility of NBL. Patients with pheochromocytoma suffering long-term excessive catecholamine exposure often experience transient postoperative hypotension as well, requiring short-term inotropics. Indeed, our patient developed postoperative hypotension that responded to dopamine infusion within 24 hours.
Once completely resected, postoperative chemotherapy is not standard treatment for INSS stage I NBL. ${ }^{11}$ However, our patient's atypical clinical manifestations prompted a course of adjuvant chemotherapy. More experience with such patients is truly needed to establish strict postoperative chemotherapeutic guidelines.

In summary, we encountered a child suffering severe hypertension and heart failure due to INSS stage I NBL, thus masquerading as pheochromocytoma. Although preoperative evaluation failed to suggest NBL, the patient was managed appropriately and successfully treated by complete tumor resection. Ultimately, a diagnosis of NBL resulted from postsurgical pathologic examination.

\section{Disclosure}

The author reports no conflicts of interest in this work.

\section{References}

1. Rich BS, La Quaglia MP. Neuroblastoma. In: Coran AG, Adzick NS, Krummel TM, et al, editors. Pediatric Surgery. 7th ed. Philadelphia: Elsevier; 2011:441-458.

2. Caty MG, Escobar MA. Adrenal tumors. In: Coran AG, Adzick NS, Krummel TM, et al, editors. Pediatric Surgery. 7th ed. Philadelphia: Elsevier; 2011:557-566.

3. Kedar A, Glassman M, Voorhess ML, et al. Severe hypertension in a child with ganglioneuroblastoma. Cancer. 1981;47(8):2077-2080.

4. Steinmetz JC. Neonatal hypertension and cardiomegaly associated with a congenital neuroblastoma. Pediatr Pathol. 1988;9(5):577-582.

5. Sendo D, Katsuura M, Akiba K, et al. Severe hypertension and cardiac failure associated with neuroblastoma: a case report. J Pediatr Surg. 1996;31(12):1688-1690.

6. Seefelder C, Sparks JW, Chirnomas D, Diller L, Shamberger RC. Perioperative management of a child with severe hypertension from a catecholamine secreting neuroblastoma. Paediatr Anaesth. 2005;15(7):606-610.

7. Cho HS, Kim HM, Park SW, et al. A case of severe hypertensive pulmonary edema associated with neuroblastoma during chemotherapy. J Korean Pediatr Soc. 2000;43(4):573-577.

8. Motta-Ramirez GA, Remer EM, Herts BR, Gill IS, Hamrahian AH Comparison of CT findings in symptomatic and incidentally discovered pheochromocytomas. AJR Am J Roentgenol. 2005;185(3):684-688.

9. McHugh K. Renal and adrenal tumours in children. Cancer Imaging. 2007;7(1):41-51.

10. Weinblatt ME, Heisel MA, Siegel SE. Hypertension in children with neurogenic tumors. Pediatrics. 1983;71(6):947-951.

11. Kushner BH, Cohn SL, Matthay KK, et al. Treatment of neuroblastoma In: Cheung NKV, Cohn SL, editors. Neuroblastoma. Berlin: Springer; 2005:123-192.
International Medical Case Reports Journal

\section{Publish your work in this journal}

The International Medical Case Reports Journal is an international, peer-reviewed open-access journal publishing original case reports from all medical specialties. Previously unpublished medical posters are also accepted relating to any area of clinical or preclinical science. Submissions should not normally exceed 2,000 words or

\section{Dovepress}

4 published pages including figures, diagrams and references. The manuscript management system is completely online and includes a very quick and fair peer-review system, which is all easy to use. Visit http://www.dovepress.com/testimonials.php to read real quotes from published authors. 